\title{
Electrochemical Behavior of Hexacyano Iron (III/II) in Frozen Aqueous Electrolytes
}

\author{
Leslie S. Books, Cherie Harris, and Kasem K. Kasem \\ Department of Natural, Information and Mathematical Sciences \\ Indiana University Kokomo \\ Kokomo, Indiana 46904-9003 USA
}

Received: October 3, 2006 Accepted: December 14, 2006

\begin{abstract}
Electrochemical studies in phases that have been solidified by freezing were carried out. A $5 \mathrm{mM}$ $\left[\mathrm{Fe}(\mathrm{CN})_{6}\right]^{-3 / 4}$ [Hexacyano Iron(III/II)] in either aqueous $0.1 \mathrm{M} \mathrm{KCl}$ or in Agar gel containing $0.1 \mathrm{M}$ $\mathrm{KCl}$ Agar were the two phase systems subject to this study. Formation of pristine ice crystals (salt free) in pure aqueous electrolyte explains smaller $\Delta \mathrm{E}_{\mathrm{p}}$ recorded in frozen agar than that in absence of Agar. Furthermore, greater capacitive current was observed in frozen agar compared to that in frozen aqueous electrolyte. The results also indicates that while a liquid-like layer $(\approx 4$ time the value of $\sqrt{2} \mathrm{Dt}$ ) is formed in frozen aqueous electrolyte at electrode/ electrolyte interface, opposite observation were recorded in frozen agar electrolyte. This evident from the thin-layer electrochemical outcome generated in frozen electrolyte, and low diffusion coefficient determined under these conditions. Deviations from the liquid state behavior at room temperature were explained on the assumption that freezing created conditions similar to those caused by application of high pressure on liquid electrochemical systems. Some kinetic data related to these systems were determined and recorded.
\end{abstract}

\section{INTRODUCTION}

Most of the performed electrochemical reactions at solid/liquid interface usually use a solid electrode and liquid electrolyte assembly. However, modern technology applications were expanded to involve all solid state electrochemical cells. The interest in the solid/solid electrochemical system was a response to the demand for increasing electrochemical efficiency. In such systems both the electrode and electrolyte are in solid state. Electrochemical studies on the interface between two solid phases started two decades ago by several investigators [1-8]. Heterogeneous solid/ liquid systems undergo spontaneous self charging resulting from self diffusion of electroactive species, reducing their electrochemical efficiency. Furthermore, convection processes in liquid electrolytes complicate the studies of the properties related to diffusion process. In order to eliminate these problems and to construct more efficient systems, the active species should be fixed to relatively immobilized sites. Understanding the electro-chemical reactions in all solid phase systems will lead to the construction of more efficient electrochemical cells. The utility of rechargeable dry batteries compared to that of solid/liquid cells such as car batteries is a good example of the advantages of all solid state electrochemical cells.

Several studies were carried out to determine electrochemical reactions in immobilized phases [9-18]. Immobilization phenomena were studied in systems that lack the liquid electrolyte character. This was achieved by entrapping the redox active substance in solid ion-exchange polymer, agar gel, or in membranes.

Understanding redox behavior under very low temperature will lead to further develop and enhance electrochemical energy devices that can operate under these conditions. Many studies of low temperature electrochemical systems on heterogeneous solid/liquid interfaces were reported [19-21]. The work done in this study was focused towards understanding the behavior of all solid state 


\begin{tabular}{|c|c|c|c|c|}
\hline Case & Electrolyte & $\begin{array}{c}\mathbf{E}^{\circ} \\
\text { Formal } \\
\text { potential }\end{array}$ & $\Delta \mathbf{E}^{\circ}$ & $\begin{array}{c}\mathbf{D} \\
\left(\mathbf{c m}^{2} \cdot \mathbf{s e c}^{-1} \mathbf{)}\right.\end{array}$ \\
\hline $1^{\text {a }}$ & Aqueous KCl & -0.014 & & $6.4 \times 10^{-6}$ \\
\hline $2^{\text {a }}$ & Agar/K Cl & -0.055 & & $1.32 \times 10^{-6}$ \\
\hline $3^{\text {b }}$ & Frozen aqu. KCl & -0.019 & 0.005 & $6.47 \times 10^{-8}$ \\
\hline $4^{\text {b }}$ & Frozen Agar $/ \mathrm{KCl}$ & 0.045 & $-0.100^{\mathrm{c}}$ & $4.95 \times 10^{-8}$ \\
\hline
\end{tabular}

Table 1. Diffusion coefficient for $\left[\mathrm{Fe}(\mathrm{CN})_{6}\right]^{-3 /-4}$ at $\mathrm{Pt}$ disc electrodes versus $\mathrm{Pt}$ reference electrode. ${ }^{\text {a }}$ Studied at room temperature; ${ }^{\mathrm{b}}$ Studied at $253 \mathrm{~K} ;{ }^{\mathrm{c}}$ in reference to Agar $/ \mathrm{K} \mathrm{Cl}$.

hexacyano-iron (III/II) redox system under freezing conditions. Systems used in this study were frozen aqueous and frozen Agar gel electrolytes.

\section{EXPERIMENTAL}

\section{a. Reagents}

$\mathrm{FeCl}_{3}, \quad \mathrm{KCl}, \quad \mathrm{K}_{3}\left[\mathrm{Fe}(\mathrm{CN})_{6}\right] \quad$ and $\mathrm{K}_{4}\left[\mathrm{Fe}(\mathrm{CN})_{6}\right]$ were of analytical grade Purified agar powder was obtained from Sigma Co. All other reagents were of at least reagent grade and were used without further purification.

\section{INSTRUMENTATION AND METHODS}

\section{a. Solid State Cell Design}

Electrochemical experiments were carried out using a $10-\mathrm{mL}$ cylindrical cell. The reference electrode, unless otherwise stated, was Pt. Validity of Platinum as a reference electrode within the potential range used in this work was tested by comparing the cyclic voltammetric redox wave of $\left[\mathrm{Fe}(\mathrm{CN})_{6}\right]^{-3 / 4}$ using $\mathrm{Ag} / \mathrm{AgCl} / \mathrm{Cl}^{-}$and using $\mathrm{Pt}$ wire electrode as reference electrodes. The cyclic voltammetric characteristics of $\left[\mathrm{Fe}(\mathrm{CN})_{6}\right]^{-3 /-4}$ redox system were the same as that generated when $\mathrm{Ag} / \mathrm{AgCL} / \mathrm{Cl}^{-}$was used as a reference electrode. The counter (auxiliary) electrode was a platinum $(\mathrm{Pt})$ wire, and the working electrodes were glassy-carbon $\left(0.07 \mathrm{~cm}^{2}\right)$ or Pt $\left(0.02 \mathrm{~cm}^{2}\right)$ disc or micro-electrodes $(10$ $\mu \mathrm{m}$ diameter). Electrodes were positioned in the cell in similar way. The $\mathrm{Pt}$ wire reference electrode was coiled around the Teflon jacket of the working electrode, the counter electrode was placed $0.5 \mathrm{~cm}$ far from both reference and working electrodes. The working electrodes were cleaned by polishing with $1 \mu \mathrm{m}$ a-alumina paste or diamond paste and rinsed with water and acetone prior to use. BAS 100B electrochemical analyzer (Bioanalytical Co.) was used to perform the electrochemical studies. Experiments were performed at -5 ${ }^{\circ} \mathrm{C}$ using antifreeze cooling liquid to be circulated around the cell.

\section{b. Impedance Measurement}

Electrochemical Impedance Spectroscopy (EIS) studies were carried out using a BAS impedance module. Faradic impedance measurements were carried out within a frequency range between $0.1 \mathrm{mHz}$ to $1 \mathrm{kHz}$. The current response was monitored by a current transducer whose sensitivity range was automatically adjusted for each frequency range examined. The data were analyzed by a Fourier transform algorithm.

\section{c. Preparation of Agar Electrolyte}

Unless otherwise stated, the gel electrolytes were prepared as follows: 3.725 $\mathrm{g}$ of $\mathrm{KCl}$ salt were dissolved in enough water to make a $100-\mathrm{mL}$ solution. The temperature of this 0.5 molar solution was increased to $95{ }^{\circ} \mathrm{C}$ then $3 \mathrm{~g}$ of purified agar were added and stirred in to complete melting. The homogeneous solution was cooled to $55^{\circ} \mathrm{C}$. 


\begin{tabular}{|c|c|c|c|c|}
\hline $\begin{array}{c}\text { Scan Rate } \\
(\mathrm{V} / \mathrm{sec})\end{array}$ & $\begin{array}{c}\text { i peak } \\
(\mu \mathrm{A})\end{array}$ & $\begin{array}{c}\sqrt{ }(2 \mathrm{Dt}) \\
\left(\mathrm{cm} \times 10^{4}\right)\end{array}$ & $\begin{array}{c}\text { i } \\
\text { Thickness of } \\
\text { active layer }\left(\times 10^{4}\right)\end{array}$ & Electrolyte \\
\hline $0.1^{\mathrm{a}}$ & 2.3 & 3.6 & 2.1 & Frozen agar \\
\hline $0.1^{\mathrm{b}}$ & 26.4 & 8.04 & 25.36 & Frozen aqueous $\mathrm{KCl}$ \\
\hline
\end{tabular}

Table 2. CV data and calculated parameters for $\mathrm{Pt}$ disc electrode $\left(0.02 \mathrm{~cm}^{2}\right)$ in frozen $\mathrm{KCl}$ solution and frozen agar containing $5 \mathrm{mM}$ of $\left[\mathrm{Fe}(\mathrm{CN})_{6}\right]^{-3 /-4}$; ${ }^{\text {a }}$ Calculated at $269{ }^{\circ} \mathrm{K}$, and ${ }^{\mathrm{b}}$ Calculated assuming measured current is due to adsorption phenomena only.

A portion of this solution was transferred to a 10-mL cylindrical cell, and the desired concentration of redox compound was dissolved. The mixture was then left to cool and form the agar gel electrolyte.

\section{PREPARATION OF SOLID -CELL ASSEMBLY}

\section{a. Solid Aqueous Assembly}

Solid electrolytes were prepared by dissolving the desired amount of $\mathrm{KCl}$ and the active redox compound in water to make $5 \mathrm{mM}$ of $\left[\mathrm{Fe}(\mathrm{CN})_{6}\right]^{-3 / 4}$ in $0.5 \mathrm{M} \mathrm{KCl}$. This electrolyte was transferred to the test tube and inserted the working, reference, and auxiliary electrodes in the test tube containing this solution. The whole assembly was subject to freezing process by first freezing it at $-50{ }^{\circ} \mathrm{C}$ and then the temperature was maintained at $-5{ }^{\circ} \mathrm{C}$ under which experiments were performed.

\section{b. Solid Gel Assembly}

Gel assembly was prepared as described before [18], and then transferred to a $15-\mathrm{mL}$ test tube. Three electrodes were placed in this gel assembly and electrodes/electrolyte assembly was subjected to the freezing process as described in above in (a).

\section{RESULTS AND DISCUSSIONS}

Cyclic voltammetric studies for $\mathrm{Pt}$ disc and micro electrodes in frozen aqueous $\mathrm{KCl}$ electrolyte containing $\left[\mathrm{Fe}(\mathrm{CN})_{6}\right]^{-3 /-4}$ were carried out. The results are displayed in Figure 1. The relationship between peak current and scan rates (or $\sqrt{ }$ scan rates) shows a diffusional behavior in the aqueous liquid state, and a surface wave behavior in frozen state. It is worth noticing that $\Delta \mathrm{Eo}^{\prime}$ (change in the formal potential) between liquid and solid state system was less than reported at the micro-electrode (see Table 1).

Furthermore, cyclic voltammetric studies for $\mathrm{Pt}$ disc and micro-electrode in frozen agar system containing $\left[\mathrm{Fe}(\mathrm{CN})_{6}\right]^{-3 /-4}$ redox system at different scan rates were carried out. The results are displayed in Figure 2. While Figure $2 \mathrm{~A}$ shows a solution type cyclic voltammetry redox wave, Figure $2 \mathrm{~B}$ is a display of the CV's obtained for $\mathrm{Pt}$ disc electrode $\left(0.02 \mathrm{~cm}^{2}\right)$ at different scan rates in the frozen agar $/ \mathrm{KCl}$ electrolyte containing $5 \mathrm{mM}\left[\mathrm{Fe}(\mathrm{CN})_{6}\right]^{-3 / 4}$. The plot of ip vs. scan rate (plot is not shown) did not generate the linear relation that reflect surface behavior. However, it rather reflects diffusion behavior. This behavior can be attributed to the ion transport rate of $\mathrm{K}^{+}$ions to and from or through the active electrode interface zone. Figure 2B shows high capacitive current compared to the faradaic current especially at high scan rate. The CV generated using micro-electrode in Figure $2 \mathrm{C}$ clearly reflects the typical characteristics of micro electrode behavior. Also both cathodic and anodic scan shows a rise of cathodic current during the cathodic scan, and the cathodic current was reduced during the anodic scan and no anodic current was recorded under this experiment conditions. It is clear that at a slow scan rate $(50 \mathrm{mV} / \mathrm{sec})$, 


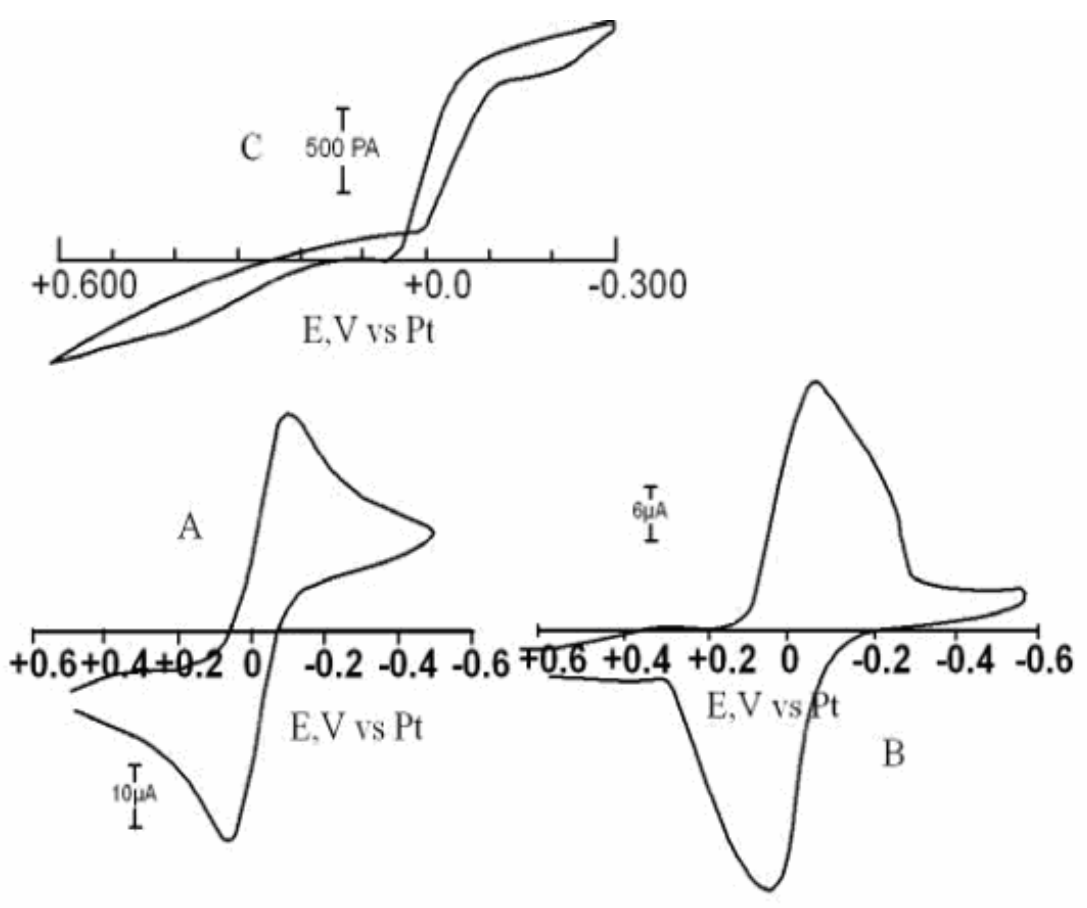

Figure 1. $\mathrm{CV}$ at $100 \mathrm{mV} / \mathrm{s}$ for $\left.5 \mathrm{mM}\left[\mathrm{Fe}(\mathrm{CN})_{6}\right]^{3-14-}: \mathrm{A}\right) \mathrm{Pt}$ disc in aqueous $\mathrm{KCl}$; $\left.\mathrm{B}\right) \mathrm{Pt}$ disc in frozen $\mathrm{KCl}$ electrolyte; and $\mathrm{C}$ ) $\mathrm{Pt}$ micro-electrode in frozen $\mathrm{KCl}$ electrolyte.

the characteristics of a micro-electrode were demonstrated in the frozen electrolytes. A comparison of the electrode behavior in frozen Agar (Figure 2B) and frozen aqueous systems (Figure 1B) shows the lack of capacitive current in solid aqueous electrolyte, and greater faradic current than that in frozen agar system. The behavior of $\mathrm{Pt}$ micro electrode (Figure $1 \mathrm{C}$ ) in the solid aqueous electrolyte was similar but not identical to that in frozen Agar (Figure 2C).

Under freezing conditions the mobility of the electrolyte is apparently reduced and the role of mass transfer diffusion that takes place in liquid electrolytes is diminished. However, upon freezing, an open solid structure associated with water system can play an important role in ion or electron transfer. In liquid systems, the thickness of an active layer at the electrode/electrolyte interface will determine the nature of the diffusion process. If the thickness of this layer is less than $\sqrt{2} \mathrm{Dt}$, then diffusion by mass transfer would be unlikely.

The thickness (i) of active layer at the electrode surface can be calculated from the following equation [22]:

$$
i_{p}=\frac{n^{2} F^{2} v V C^{0}}{4 R T}
$$

where $V$ is the volume of the active layer, and $v$ is the scan rate in Volts/second (or $\mathrm{V} / \mathrm{sec}$ ).

Considering the range of active layer thickness near micro-electrode the following equation was used to calculate diffusion coefficient $D$,

$$
i_{\text {lim }}=4 n r F D C
$$

The calculated $D$ values displayed in Table 1 clearly show that $D$ in frozen aqueous or in frozen agar is 100 times less than reported at room temperature in liquid aqueous media [18]. Because the conditions that allow approximate calculations of diffusion coefficient (D), using the Stocks-Einstein equation $\left(D_{1} \cdot \eta_{1}=D_{2} \cdot \eta_{2}\right)$ where $\eta$ is the viscosity in poise) resemble the status of liquid aqueous $\mathrm{KCl}$ and Agar systems, we used this formula to calculate the approximate hypothetical viscosity that the frozen systems may have. The calculated $\eta$ using this formula was 88.04 poise for the media described in case 3 (Table 1) and 


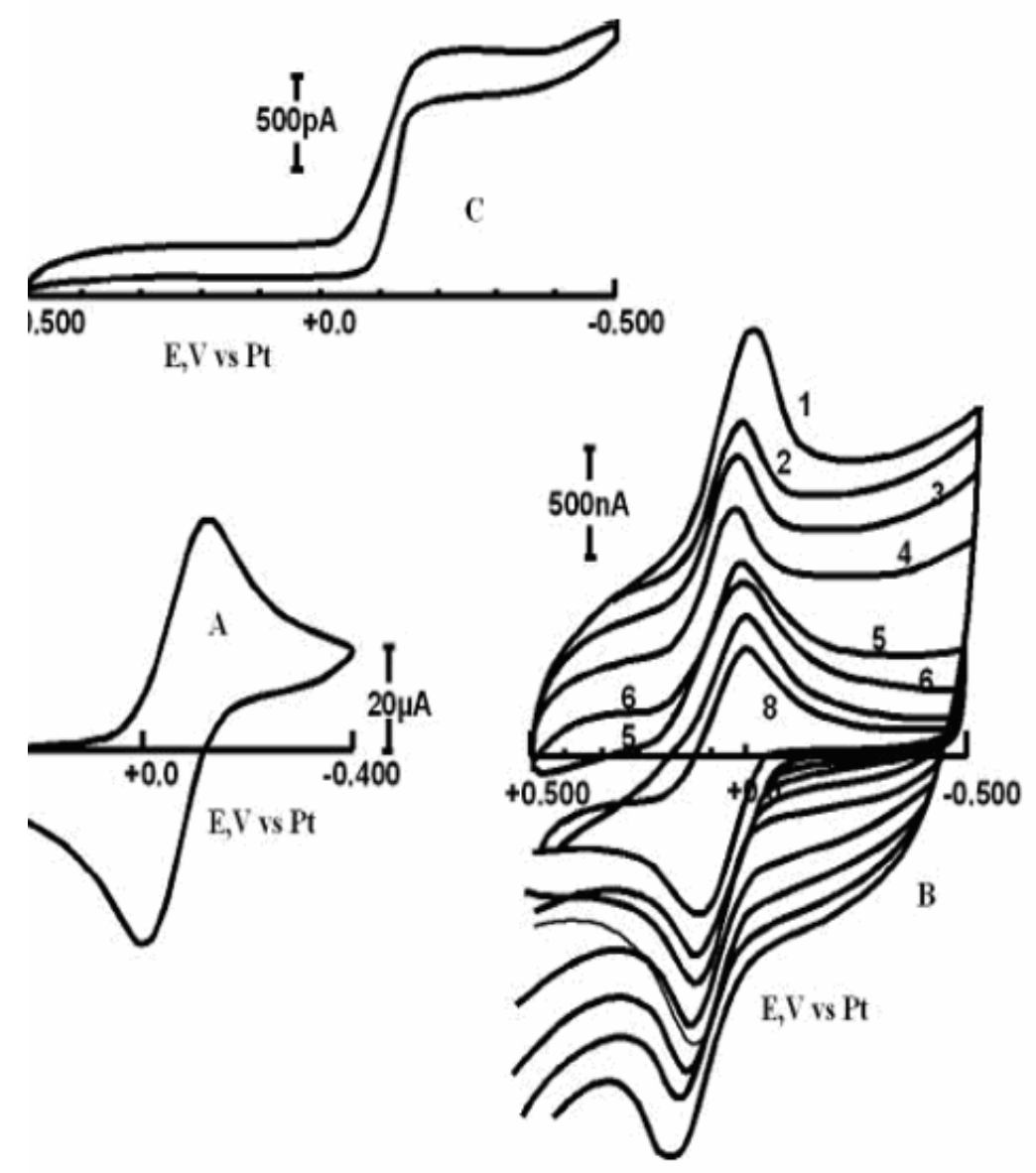

Figure 2. $\mathrm{CV}$ for $5 \mathrm{mM}\left[\mathrm{Fe}(\mathrm{CN})_{6}\right]^{3-14-}$ in Agar $/ \mathrm{KCl}$ system: A) Pt disc at $100 \mathrm{mV} / \mathrm{s}$; B) Pt microelectrode in frozen Agar $/ \mathrm{KCl}$ at $50 \mathrm{mV} / \mathrm{s}$; C) Pt disc in frozen Agar/ $\mathrm{KCl}$ at 1) 500,2$) 400,3) 300$, 4) 200 , 5) 100, 6) 70, 7) 50 and 8) $20 \mathrm{mV} / \mathrm{s}$.

115.07 poise for that in case 4 . In spite of the limitation in using this formula in liquid systems, the calculated $\eta$ clearly indicates that the diffusion by mass transfer can not take place under these conditions, although the thickness of the active layer (calculated from equation 1$)$ is larger than $(\sqrt{ } 2 \mathrm{Dt})$ as listed in Table 2. This confirms what previously reported [23] at electrode /frozen aqueous electrolyte interface. The greater peak current listed in Table 2 in absence of mass transfer may indicate that the charge transfer took place by different route. In case of frozen agar electrolyte, the thickness of the active layer was in contrary to the pure frozen aqueous electrolyte is less than the $\sqrt{2}$ Dt. The high capacitive current observed for the frozen agar CV (Figure 2B) indicates that agar macromolecules were aligned to create small capacitor at the interface with the electrode surface.

\section{a. Pressure Equivalent to Phase Change}

Working under the condition of solidified electrolyte (caused by freezing) would raise a question about the mechanism of charge transfer that took place under these conditions. In liquid electrolytes, the charge transfer is accompanied by a volume change especially if the process took place through outer-sphere mechanism. The change would take place in the volume of solvation molecule. The fact that the thickness of the active layer is larger than $(\sqrt{2 D t})$, even under condition of solid electrolyte, the size of this layer is not enough to accommodate the volume change that results from charge transfer. This means that the charge transfer may result in bond compression or elongation. This phenomenon was noticed [24] when an electrochemical system in liquid electrolyte 
was subject to very high pressure (several kilo pars).

Correlation between the change in the volume of electro-active molecule and that of the change in formal potential $\mathrm{E}^{\circ}$ can be derived as follows:

$$
\begin{aligned}
\Delta G^{0} & =-n E^{0} F \\
E^{0} & =-\frac{\Delta G^{0}}{n F} \\
\left(\frac{\delta E^{0}}{\delta P}\right)_{T} & =-\left(\frac{\delta \Delta G^{0}}{\delta P}\right)_{T} \times \frac{1}{n F} \\
\left(\frac{\delta E^{0}}{\delta P}\right)_{T} & =-\frac{\Delta V^{0}}{n F} \\
\Delta V^{0} & =-\left(\frac{\delta E^{0}}{\delta P}\right)_{T} n F
\end{aligned}
$$

In liquid electrolytes the change of the volume $\left(\Delta \mathrm{V}^{\circ}\right)$ comes from the outer sphere molecules in the solvation layer rather than from the change in the bond lengths (compression or expansion). On the other hand in the solid state we assume that $\Delta \mathrm{V}^{\circ}$ $=0$. According to equation 7 , this can be possible when

$$
\left(\frac{\delta E^{0}}{\delta P}\right)_{T}=0 .
$$

Under this assumption we should have a constant value for the formal potential $E^{\circ}$. However, the data listed in Table 1 show that a deviation from the formal potential of the studied system took place when freezing or when the system is no longer in the liquid state. The phenomena of the change of the formal potential were noticed with application of high pressure on the liquid system. It has been reported [24] in the formal potential of the $\left[\mathrm{Fe}(\mathrm{CN})_{6}\right]^{-3 /-4}$ system in a liquid electrolyte of $3.93 \times 10^{-5}$ V/atm took place when the system was subject to pressure.

If we consider that the changes in the formal potential of $\left[\mathrm{Fe}(\mathrm{CN})_{6}\right]^{-3 /-4}$ when it was subject to phase change (from liquid electrolyte to gel or solid electrolyte) is similar to that caused by pressure, then we can estimate the pressure equivalent of the phase change. The change in the formal potential due to phase change listed in Table $1\left(\Delta \mathrm{E}^{\circ}\right)$ indicates that freezing the liquid aqueous solution of $\left[\mathrm{Fe}(\mathrm{CN})_{6}\right]^{-3 / 4}$ generates a $3.5 \mathrm{mV}$ change in the formal potential. This is equivalent to applying 89 atm . The data listed in Table 1 suggests that the pressure equivalent of freezing gel is approximate $2500 \mathrm{~atm}$. The volume of both the reference and counter electrodes components will remain constant because $\mathrm{Pt}$ wire was used as a reference and counter electrodes; the change is due to the change in the volume of the redox ion. In the case of frozen aqueous $\mathrm{KCl}$ electrolyte, the positive shift in the formal potential caused by phase change refers to decrease in the effective volume of the electroactive redox system that includes $\left[\mathrm{Fe}(\mathrm{CN})_{6}\right]^{-3 / 4}$. The volume decrease can be attributed to the double layer restructuring that took place after temperature change caused by charge transfer at this solution like interface. Possible bond compression may explain such decrease, but we don't have extra data to support this possibility. The negative value of $(\delta E / \delta P)_{T}$ recorded for frozen agar system may indicates an increase in volume of Agar/redox ion complex.

b. Impedance Studies

Impedance measurements for the studied system are displayed in Figure $3 \mathrm{~A}$ (frozen electrolyte), and 3B (Agar). Comparing the values of $Z$ (real and imaginary) clearly indicates greater impedance at the electrode/Agar interface than that at electrode/frozen electrolyte interface. The Nyquest plot in Figure 3 also shows a diffusional behavior of this immobilized assembly and no sign of charge saturation when measurements were performed at $0.0 \mathrm{~V}$ vs $\mathrm{Pt}$. The resistance at this interface would be expected to be in series with the charge transfer process which would be at high frequency. Resistance for the faradic process $\left(R_{f}\right)$ can be determined from the diameter of charge transfer semicircle at high frequency. Frequency $f$ that matches the top point at this semicircle is called relaxation frequency. The quantity $\omega_{c}\left(\right.$ where $\left.\omega_{c}=2 \pi f\right)$ can then 


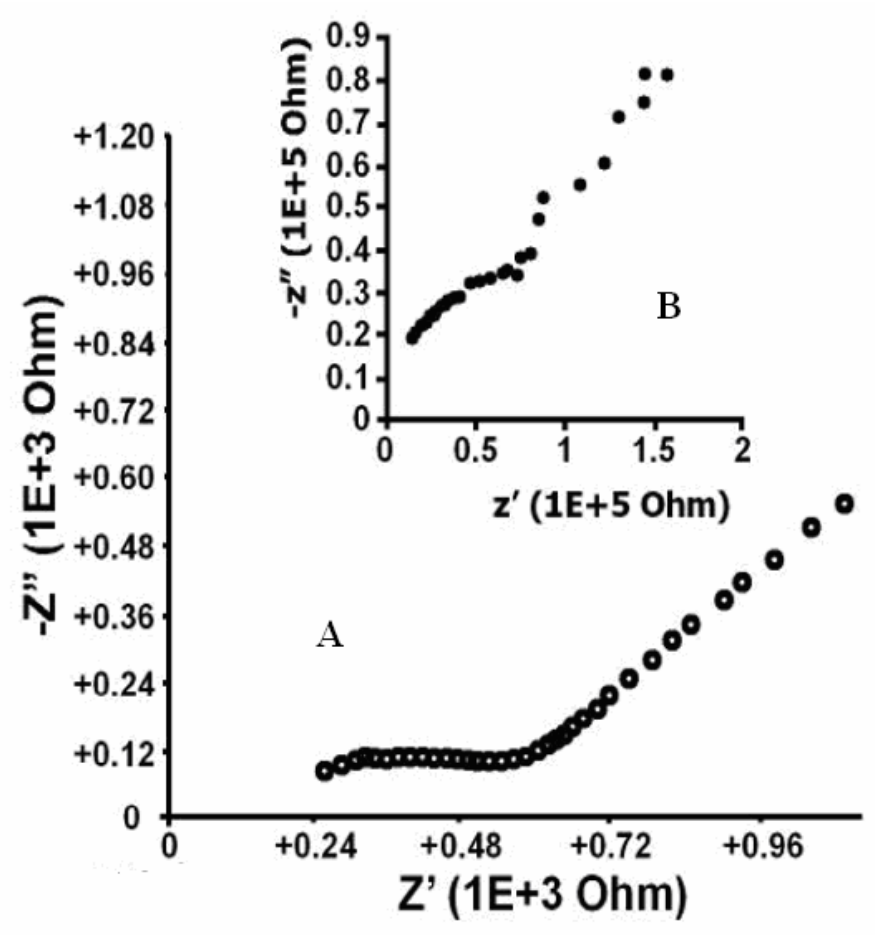

Figure 3. Nyquist plot at $0.0 \mathrm{~V}$ vs Pt electrode for $\left.5 \mathrm{mM}\left[\mathrm{Fe}(\mathrm{CN})_{6}\right]^{3-4-}: \mathrm{A}\right)$ at $\mathrm{Pt}$ disc in frozen $\mathrm{KCl}$ electrolyte; and B) at Pt disc in Agar / $/ \mathrm{KCl}$.

be calculated and integrated into the following relationship that allows us to determine $R_{f}$ :

$$
\omega_{c}=\left(R_{f} C_{d l}\right)^{-1} \text {. }
$$

Calculation of $C_{d l}$ is based on the Bud's plot of the following equation:

$$
\begin{gathered}
\log Z=\frac{1}{2} \log \left[R^{2}+\left(\frac{1}{2 \pi f C}\right)^{2}\right] \\
\log Z=\log R-0.7998-\log f-\log C
\end{gathered}
$$

The plot of $\log (Z)$ versus $\log (f)$ should give a straight line with slop of -1 . The value of $Z$ when $\log (f)=0$ can be used to calculate $C$, considering the value of $R$ at $f=1$. $C$ was determined to be $6.66 \times 10^{-7} \mathrm{~F}$. This correspondent to an $R_{F}$ quantity of $853.5 \Omega$. Considering that,

and

$$
R_{F}=R T /\left(n i_{0} F\right)
$$

$$
i_{0}=n F k^{0} A C_{0}^{(1-\alpha)} C_{R}{ }^{\alpha}
$$

a was determined and found to approach 0.5 (0.495); $C_{o}$ and $C_{R}$ were found to be of equal quantity $(5 \mathrm{mM} / \mathrm{L})$, and the calculated value of $\mathrm{k}^{\mathrm{O}}$ was determined to be $2.64 \times 10^{-3}$ $\mathrm{cm} / \mathrm{sec}$. This amount is greater than that reported [25] for immobilized $\left[\mathrm{Fe}(\mathrm{CN})_{6}\right]^{-3 / 4}$ in highly cross linked polymer films in aqueous electrolytes.

Equation 1 assumes the system of outer sphere charge transfer mechanism. The CV for $5 \mathrm{mM}$ of $\left[\mathrm{Fe}(\mathrm{CN})_{6}\right]^{-3 /-4}$ generates results that do not support the mechanism of outer sphere. At $298 \mathrm{~K}$ and $269 \mathrm{~K}$, $\mathrm{i}_{\mathrm{p}}$ was $6.05 \times 10-5$ and $2.64 \times 10-5 \mathrm{~A}$, respectively. Such quantities correspond to a change in volume of active layer equal to $7.8 \times 10-5 \mathrm{~L}$. This volume change is equivalent to a 0.2 $\mathrm{mV}$ change in the formal potential of $\left[\mathrm{Fe}(\mathrm{CN})_{6}\right]^{-3 / 4}$ redox system. This quantity is far smaller than the reported $5 \mathrm{mV}$ for frozen aqueous $\left[\mathrm{Fe}(\mathrm{CN})_{6}\right]^{-3 /-4}$ system. This indicates that the change in the formal potential is due to mainly on the effect of the pressure that freezing caused. 


\section{CONCLUSIONS}

The observed electrochemical
behavior of $\left[\mathrm{Fe}(\mathrm{CN})_{6}\right]^{-3 /-4}$ in frozen electrolytes may be similar to that observed at high pressure. Under such condition of high pressure, bond compression, elongation is likely to take place. The lower current than excepted under low temperature can be explained on the bases of high pressure-like effect caused by freezing. The change in the solvation layer (if the outer-sphere mechanism is assumed) becomes very slow. This is because the reorganizational energy of $\mathrm{H}_{2} \mathrm{O}$ molecules in solid electrolyte is preceded with greater energy step which requires phase change (solid-liquid change). The fact that even under freezing conditions, a liquid-type layer can exist at electrode/electrolyte interface, suggests that these systems can be used in controlling growth of thin films. This is because of the limits in the mass transfer process under these conditions.

\section{REFERENCES}

1. Cox, James A.; Wolkiewicz, Anna M.; Kulesza, Pawel J., J. Solid State Electrochemistry, 2(4), (1998) 247.

2. Wu, Ping; Cai, Chenxin., J. Electroanal. Chem., 576(1), (2005) 49.

3. He, Y.; Yao, Hongyu; Li, Zhengwei; Qi, Huibin; Stott, F. H., Oxidation of Metals, 53(3/4), (2000) 323.

4. Pawel J. Kulesza, J. Electroanal. Chem., 289, (1990) 103.

5. Ogata, Naoya; Watanabe, Masayoshi. J. of Kino Zairyo, 11(4), (1991) 24.

6. Kulesza, Pawel J.; Galus, Zbigniew, J. Electroanal. Chem., 323(1-2), (1992) 261.

7. Kulesza, Pawel J.; Faulkner, Larry R.; Chen, Jie; Klemperer, Walter G, J.A.C.S., 113(1), (1991) 379.
8. Pizzini, S.; Bianchi, G, Chimica e I'Industria, 54(3), (1972) 224.

9. C.E.D Chindsey and R.W. Murra, Science 231, (1986) 25.

10. E. Dalton, N..Surridge, J. Jernigan, K. Wilbourn, and R.W. Murray, J. Chem. Phys., 141, (1990) 143.

11. T.T. Wooster, M. Longmire, H. Zhang , M. Watanabe and R.W. Murray, J. Electroanal. Chem., 64, (1992) 1132.

12. D.R. Rosseinsky, J.S. Tonge, J. Berthelot and J.F. Cassidy, J. Chem. Soc. Faraday Trans. 83, (1987) 231.

13. P.J. Kulesza, Inorganic Chem., 29(1990) 2395.

14. P.J. Kulesza, G. Chelmecki and B. Galadyk, J. Electroanal. Chem., 347, (1993) 417.

15. P.J. Kulesza, J.Electroanal. Chem., 289, (1990) 103.

16. Z. Gao, G. Wang, P. Li and Z. Zhao, J. Electrochimica. Acta, 36, (1991) 147.

17. K. Ogura, J. Applied Electrochem. 16, (1986) 736.

18. K. K. Kasem, J., New Mat. Electrochem. Systems , 8(3), (2005) 189.

19. Bond, A. M.; Sweigart, D. A., Inorganica Chimica Acta, 123(3), (1986) 167.

20. O'Brien, Paul; Sweigart, Dwight A, J. Chemical Society, Chemical Communications, (3), (1986) 198.

21. Van Duyne, Richard P.; Reilley, Charles N, Analytical Chemistry, 44(1), (1971) 142.

22. A.J. Bard and L.R. Faulkner, Electrochemical Methods; fundamentals and Applications (John Willey \& Sons, New York, 1980) Chapter 10.

23. V. Tsionsky, D. Zagidulin, and E. Gileadl., J. Phys. Chem. B, 106(51), (2002), 3089.

24. J. I. Sachinldis, R. D. Shalders, and P. A. Tregloan, Inorganic Chem., 33, (1994) 6180.

25. K. K. Kasem and F. A. Schultz, J. Inorganic and Organometallic Polymers, 4(4), (1994) 377.

Subscribe to the American Journal of Undergraduate Research Four issues per volume (June, September, December, March) \$20/year for individuals \$40/year for institutions Including postage for subscribers in the US, Mexico and Canada 